Johannes P. Van de Leur Jan H. Zwaveling

Bert G. Loef

Cees P. Van der Schans

\section{Endotracheal suctioning versus minimally invasive airway suctioning in intubated patients: a prospective randomised controlled trial}

Published online: 17 May 2003

(C) Springer-Verlag 2003

The online version of the original article can be found at http://dx.doi.org/10.1007/s00134-003-1639-9

\section{Intensive Care Med (2003) 29:426-432}

In the printed version of the article, the authors names of the first and the fourth author appeared incorrectly. The correct names are as follows: Johannes P. Van de Leur, Cees P. Van der Schans.

J. P. Van de Leur $(\varangle) \cdot$ C. P. Van der Schans

Centre for Rehabilitation,

University Hospital Groningen,

PO Box 30.001, 9700 RB Groningen, The Netherlands

e-mail: j.p.van.de.leur@rev.azg.nl

Tel.: +31-50-3614760

Fax: +31-50-3611708

J. H. Zwaveling

Dept. of General Surgery and Intensive Care,

University Hospital Groningen,

Groningen, The Netherlands

B. G. Loef

Dept. Cardio-Thoracic Surgery and Intensive Care,

University Hospital Groningen,

Groningen, The Netherlands

C. P. Van der Schans

University for Professional Education,

Hanzehogeschool and Centre for Rehabilitation,

University Hospital Groningen,

Groningen, The Netherlands 